\title{
Responses of Tomato Genotypes to Avirulent and Mi-Virulent Meloidogyne javanica Isolates Occurring in Israel
}

\author{
Ionit Iberkleid, Rachel Ozalvo, Lidia Feldman, Moshe Elbaz, Bucki Patricia, and Sigal Brown Horowitz
}

First, second, third, fifth, and sixth authors: Department of Entomology, Nematology and Chemistry units, Agricultural Research Organization (ARO), the Volcani Center, Bet Dagan, Israel; first author: Department of Plant Pathology and Microbiology, The Robert H. Smith Faculty of Agriculture, Food and Environment, The Hebrew University of Jerusalem, Rehovot, Israel; and fourth author: Negev Research and Development Station, Habsor Farm, Israel. Accepted for publication 19 November 2013.

\begin{abstract}
Iberkleid, I., Ozalvo, R., Feldman, L., Elbaz, M., Bucki, P., and Brown Horowitz, S. 2014. Responses of tomato genotypes to avirulent and Mi-virulent Meloidogyne javanica isolates occurring in Israel. Phytopathology 104:484-496.

The behavior of naturally virulent Meloidogyne isolates toward the tomato resistance gene $\mathrm{Mi}$ in major tomato-growing areas in Israel was studied for the first time. Virulence of seven selected isolates was confirmed over three successive generations on resistant (Mi-carrying) and susceptible (non-Mi-carrying) tomato cultivars. Diagnostic markers verified the predominance of Meloidogyne javanica among virulent isolates selected on resistant tomato cultivars or rootstocks. To better understand the determinants of nematode selection on $M i$-carrying plants, reproduction of $M i$-avirulent and virulent isolates Mjav1 and Mjv2, respectively, measured as eggs per gram of root, on non-Mi-carrying, heterozygous $(\mathrm{Mi} / \mathrm{mi})$ and homozygous $(\mathrm{Mi} / \mathrm{Mi})$ genotypes was evaluated. Although no reproduction of Mjav1 was observed on $\mathrm{Mi} / \mathrm{Mi}$ genotypes,

the $M i$ gene. Histological examination of giant cells induced by $M i-$ virulent versus avirulent isolates confirmed the high virulence of Mjv2 on $\mathrm{Mi} / \mathrm{mi}$ and $\mathrm{Mi} / \mathrm{Mi}$ genotypes, allowing the formation of well-developed giant-cell systems despite the $M i$ gene. Analysis of the plant defense response in tomato $\mathrm{Mi} / \mathrm{Mi}, \mathrm{Mi} / \mathrm{mi}$, and $\mathrm{mi} / \mathrm{mi}$ genotypes to both avirulent and virulent isolates was investigated by quantitative real-time polymerase chain reaction. Although the jasmonate (JA)-signaling pathway was clearly upregulated by avirulent and virulent isolates on the susceptible (not carrying $\mathrm{Mi}$ ) and heterozygous $(\mathrm{Mi} / \mathrm{mi}$ ) plants, no change in signaling was observed in the homozygous $(\mathrm{Mi} / \mathrm{Mi})$ resistant line following incompatible interaction with the avirulent isolate. Thus, similar to infection promoted by the avirulent isolate on the susceptible genotype, the $M i$-virulent isolate induced the JA-dependent pathway, which might promote tomato susceptibility during the compatible interaction with the homozygous $(\mathrm{Mi} / \mathrm{Mi})$ resistant line. These results have important consequences for the management of $M i$ resistance genes for ensuring sustainable tomato farming.
\end{abstract} some reproduction was consistently observed on $\mathrm{Mi} / \mathrm{mi}$ plants; reproduction of Mjv2 on the homozygous and heterozygous genotypes was similar to that on susceptible cultivars, suggesting a limited quantitative effect of
Additional keywords: dosage effect, root-knot nematode.
Root-knot nematodes (RKNs, Meloidogyne spp.) are of major concern to solanaceous cropping, including tomato and pepper, in most production areas in Israel (46). The most important infestations are frequently observed in the Arava desert region, the hilly Negev, the northern Negev, and the Hasharon region, probably because vegetable crops are extensively grown in light sandy soils, which favor RKN multiplication $(16,46,62)$. The two prevalent species reported to infest tomato-production greenhouses in Israel are Meloidogyne javanica and M. incognita, with occasional infestations reported for $M$. hapla. The damage caused by these species depends largely on RKN population density and whether resistant cultivars or rootstocks, which are considered an effective nematode-management tool, are being utilized.

Tomato (Solanum lycopersicum) is considered one of the most important vegetable crops in Israel. Resistance in tomato is conferred by the single dominant gene $\mathrm{Mi}$, which was introgressed

Corresponding author: S. B. Horowitz;

E-mail address: sigalhor@ volcani.agri.gov.il

I. Iberkleid and R. Ozalvo contributed equally to this work.

* The $\boldsymbol{e}$-Xtra logo stands for "electronic extra" and indicates that the online version contains two supplemental tables and one supplemental figure. Figures 3 and 4 appear in color online.

http://dx.doi.org/10.1094/PHYTO-07-13-0181-R

(C) 2014 The American Phytopathological Society from the wild-type relative of tomato, Lycopersicon peruvianum (60), and is present in all modern resistant fresh-market and processing cultivars (70). This gene confers resistance to three species of RKNs ( $M$. arenaria, $M$. incognita, and $M$. javanica) as well as isolates of potato aphids and white flies in tomato $(6,11,23,42,56)$. For $>65$ years, this gene has been the only source of resistance to RKNs in all available tomato cultivars worldwide, and may be considered a very stable resistance gene in terms of durability.

Previous microscopic studies have demonstrated that $M i$ functions only in a narrow temporal window; its function depends on a rapid, local defense response triggered by direct or indirect interaction between the $M i$ product and highly specific elicitors from the nematode $(11,23,56)$. Although nematodes are attracted to and penetrate roots similarly in resistant and susceptible plants, in the former there is no development of a feeding site. Instead, localized tissue necrosis or a hypersensitive response (HR) occurs at or near the site where feeding would normally be initiated $(11,56)$.

Although $\mathrm{Mi}$ should block nematode development at an early stage of interaction, it does not confer total immunity. First, resistance breaks down when soil temperatures are $>28^{\circ} \mathrm{C}$ (1), as is prevalent in Israel (45). Second, natural populations of Meloidogyne spp. and the occurrence of $M i$-virulent populations of Meloidogyne spp. (pathotype or biotype) that have succeeded to reproduce on resistant tomato genotypes are frequently reported $(6,12,67)$. Moreover, artificial selection of virulent lineages from 
progeny of avirulent Meloidogyne isolates was demonstrated by repeated inoculations onto $\mathrm{Mi}$-resistant tomato genotypes under laboratory and greenhouse conditions in relatively few generations $(14,34,41)$.

Signaling pathways and proximal defenses responsible for $\mathrm{Mi}$ mediated resistance have not yet been elucidated but this form of resistance appears to require a plant signaling compound, at least partially involving the salicylic acid (SA) pathway, as studied by Branch et al. (11). In this context, Bhattarai et al. (5) showed that jasmonate (JA) signaling is not involved $M i$-mediated resistance; however, negative pathway crosstalk may occur between the JAand SA-signaling pathways, in which $M i$-dependent, SA-mediated resistance to RKNs might be suppressed by JA signaling (26). Nevertheless, the role of JA, SA, and ethylene (ET) defensesignaling pathways in regulating the $M i$ resistance in response to avirulent and virulent nematodes has yet to be defined $(5,17,61)$. Thus, it would be of interest to develop a more comprehensive understanding of the changes in plant defense response gene expression in the presence of avirulent and $M i$-virulent biotypes.

In an attempt to elucidate the factors affecting the expression of $M i$ resistance, the contributions of $M i$ dosage and genetic background to resistance failure have been studied (19). Several years ago, Tzortzakakis et al. (67) showed that reproduction of three isolates with partial virulence was much greater on tomato genotypes heterozygous for the $M i$ gene than on $M i$-homozygous genotypes. Similarly, Jacquet et al. (32) indicated that reproduction of the nematode $M$. incognita is significantly higher on heterozygous tomato genotypes than on homozygous ones, further suggesting a dosage effect of the $M i$ gene. More recently, Maleita et al. (40) have shown that an increasing number of $M i$ alleles $(n=0,1$, or 2$)$ is associated with a decrease in the reproduction factor of $M$. hispanica on tomato, again suggesting a possible dosage effect of the $M i$ gene. Taken together, these findings position the allelic condition as an important determinant in the interaction between $M i$-containing plants and avirulent or partially virulent RKNs. However, the pathogenicity of local avirulent and $M i$-virulent populations associated with different $M i$ dosages and genetic backgrounds needs to be evaluated.

In Israel, resistant cultivars are not always effective. The occurrence of virulent isolates is becoming a serious problem, because they overcome the plant's resistance and increase exponentially in fields with inappropriate crop management. It is therefore important to understand the causes of possible $M i$-resistance failure, and to evaluate the responses of different genotypes differing in their allelic condition and genetic background following interaction with avirulent and $M i$-virulent isolates.

The objective of the present study was to provide, for the first time, a detailed characterization of Mi-virulent Meloidogyne isolates occurring in Israel. The reproduction of local wild avirulent and selected $M i$-virulent $M$. javanica isolates was evaluated on tomato ( $S$. lycopersicum) genotypes carrying or not carrying the $M i$ gene $(M i / M i, M i / m i$, and $m i / m i)$. In addition, a detailed histological and molecular characterization of the interaction between avirulent and $M i$-virulent $M$. javanica nematodes with three tomato genotypes differing in $M i$-allelic condition was conducted.

\section{MATERIALS AND METHODS}

Plant material and growth conditions. Fourteen tomato (S. lycopersicum) genotypes originating from the Faculty of Agriculture, Food, and Environment's tomato breeding stock collection were used in the current experiments. Their main characteristics were as follows: five genotypes were susceptible $(\mathrm{mi} / \mathrm{mi})$ fixed lines, five were homozygous for the resistance gene $M i$ $(\mathrm{Mi} / \mathrm{Mi})$, and the four remaining genotypes were heterozygous for the $\mathrm{Mi}$ gene $(\mathrm{Mi} / \mathrm{mi})$ resulting from different homozygous genotype crossbreeding (Table 1). 'Casaque Rouge' (line 2128; susceptible) and 'Anahu' (line 2129; resistant, homozygous for the $M i$ gene) tomato and the heterozygous line 2130 (39) were used as the core genotypes to analyze histological and molecular responses. All seed were germinated in trays of commercial, sterilized compost soil in a greenhouse and transplanted at the twoleaf stage into plastic pots filled with sandy loam soil. Transplanted seedlings were allowed to grow for an additional 2 weeks before nematode inoculation. Tomato seedlings and transplanted plants were fertilized with slow-release fertilizer (Osmocote Smart-Release Plant Food; Scotts-Sierra Horticultural Products Co., Marysville, $\mathrm{OH}$ ), and maintained in the greenhouse under controlled conditions $\left(23\right.$ to $25^{\circ} \mathrm{C}$, photoperiod of 16 and $8 \mathrm{~h}$, light and darkness, respectively). Prior to inoculation, all tomato genotypes were verified for their $M i$ allelic condition by polymerase chain reaction (PCR)-based methods according to Williamson et al. (69) (Supplemental Figure 1). PCR was conducted using the sequence-characterized amplified region (SCAR) primer pair Mi23F (5'-TGG AAA AAT GTT GAA TTT CTT TTG-3') and Mi23R (5'-GCA TAC TAT ATG GCT TGT TTA CCC-3'), according to Seah et al. (57). In addition, the PMi set of primers PMiF3 (5' CCT GTG ATG AGA TTC CTC TTA G 3') and PMiR3 (5' ACC CTT TGT TGA GCG ACT TTG CAG C $3^{\prime}$ ) were used to amplify the region of the $M i$ gene according to El Mehrach et al. (22).

Nematode isolate collection and inoculum preparation. A nematode survey was carried out in four tomato-growing areas in Israel cultivated with commercial resistant tomato cultivars or rootstocks for at least 2 years and in which heavy nematode

TABLE 1. Main characteristics of tomato genotypes used in this study

\begin{tabular}{|c|c|c|c|c|c|}
\hline Type & Code & $M i$ allelic condition & Parent code & Branching pattern & Fruit shape \\
\hline \multicolumn{6}{|c|}{ Regular tomato } \\
\hline \multirow[t]{3}{*}{ Fixed lines } & $\mathrm{X}-5099$ & $M i-1 / M i-1$ & $\ldots$ & Indeterminant & Round \\
\hline & $X-5135$ & $M i-1 / M i-1$ & $\ldots$ & Indeterminant & Flat \\
\hline & X-6091 & $m i / m i$ & $\ldots$ & Indeterminant & Globe \\
\hline \multirow{2}{*}{$\mathrm{F}_{1}$ hybrids } & V-2034 & $M i-1 / m i$ & $X-5099 \times X-5326$ & Indeterminant & Globe \\
\hline & V-1059 & $M i-1 / m i$ & $X-5135 \times X-5073$ & Indeterminant & Globe \\
\hline \multicolumn{6}{|l|}{ Cherry tomato } \\
\hline & SA476-1 & $m i / m i$ & $\ldots$ & Indeterminant & Round \\
\hline & SA557-1 & $m i / m i$ & $\ldots$ & Indeterminant & Round \\
\hline \multirow{2}{*}{$\mathrm{F}_{1}$ hybrids } & SV1340 & $M i-1 / m i$ & SA502-1 × SA476-1 & Indeterminant & Elongated \\
\hline & SV1335 & $M i-1 / m i$ & SA552-1 × SA557-1 & Indeterminant & Round \\
\hline \multicolumn{6}{|l|}{ Control } \\
\hline & 2129 & $M i-1 / M i-1$ & $\ldots$ & Indeterminant & Flat \\
\hline & 2130 & $M i-1 / m i$ & $\ldots$ & Indeterminant & $\ldots$ \\
\hline
\end{tabular}


infestation was recorded. In total, seven Meloidogyne populations from distinct locations were further characterized (Table 2). To confirm isolate virulence against the $M i$ gene, all selected natural isolates were tested for their reproduction on 'Avigail 870' $(\mathrm{mi} / \mathrm{mi})$ and 'Sherlot 1402' $(\mathrm{Mi} / \mathrm{mi})$ tomato in pot experiments under controlled conditions ( 23 to $25^{\circ} \mathrm{C}$, photoperiod of 16 and $8 \mathrm{~h}$, light and darkness, respectively). To eliminate population heterogeneity, a single egg mass was carefully selected from each isolate raised from each greenhouse population, which was then used to reinoculate susceptible $(\mathrm{mi} / \mathrm{mi})$ and resistant $(\mathrm{Mi} / \mathrm{mi})$ tomato plants. Given that $M$. javanica has a mitotic parthenogenetic mode of reproduction (64), all egg masses produced on the following generation were considered a cloned line. To confirm isolate virulence on $M i$ plants, the seven isolates were allowed to propagate over three successive generations on resistant Sherlot 1402 and susceptible Avigail 870 plants, and nematode virulence was evaluated after each generation. For all inoculation tests and for species-specific identification, all $M i$-virulent nematode isolates were maintained in the greenhouse on resistant Sherlot 1402 whereas the avirulent nematode populations were routinely reared on susceptible Avigail 870. Nematode inoculums was obtained according to Hussey and Baker (29), and eggs were extracted from infected roots by processing in $0.05 \%$ ( vol/vol) $\mathrm{NaOCl}$ in a Waring (Waring, Torrington, CT) commercial blender for $2 \mathrm{~min}$ at high speed. Blended roots were passed through a set of three sieves of 300,60 , and $30 \mu \mathrm{m}$, allowing collection of pure egg solution in the lower sieve. For in vitro inoculation, eggs were placed in a sterile Whatman filter holder (Whatman International Ltd., Dassel, Germany) with a cellulose-acetate filter membrane (pore size $5 \mu \mathrm{m}$; Sartorius Stedim Biotech $\mathrm{GmbH}$, Goettingen, Germany). Eggs on the filter were exposed for $10 \mathrm{~min}$ to $0.01 \%$ (wt/vol) mercuric chloride $\left(\mathrm{HgCl}_{2}\right)$ (Sigma-Aldrich, St Louis) followed by $0.7 \%$ streptomycin solution (Sigma-Aldrich) and three washing steps in $50 \mathrm{ml}$ of sterile distilled water (33). Sterile eggs were then collected from the membrane and placed on $25-\mu \mathrm{m}$-opening sieves in $0.01 \mathrm{M}$ morpholinoethanesulfonic acid (Sigma-Aldrich) buffer under aseptic dark conditions for 3 days. Freshly hatched preparasitic second-stage juveniles (J2s) were then collected in a 50-ml falcon tube. For in vitro root inoculation, the seed of three genotypes differing in $M i$ allelic condition$2128(\mathrm{mi} / \mathrm{mi}), 2130(\mathrm{Mi} / \mathrm{mi})$, and $2129(\mathrm{Mi} / \mathrm{Mi})$-were soaked in sterile water for $1 \mathrm{~h}$ at $32^{\circ} \mathrm{C}$, treated with $1.4 \% \mathrm{NaOCl}$ for $10 \mathrm{~min}$, washed several times with sterile water for $5 \mathrm{~min}$, and then plated on standard-strength Gambourg's B5 salts medium (Duchefa, Haarlem, The Netherlands) supplemented with 2\% (wt/vol) sucrose and solidified with $0.8 \%$ (wt/vol) Gelrite (Duchefa). Seed were kept in a growth chamber at $26^{\circ} \mathrm{C}$, with a photoperiod of 16 and $8 \mathrm{~h}$, light and darkness, respectively at $120 \mu \mathrm{mol} \mathrm{m} \mathrm{m}^{-2} \mathrm{~s}^{-1}$. One week after germination, tomato root sections were subcultured, one root per petri dish (Miniplast, EinShemer, Israel) containing B5 medium. Petri dishes were kept horizontally (for further root growth and branching) for an additional week at $26^{\circ} \mathrm{C}$ under dark conditions prior to nematode inoculation. Inoculation was performed with 250 sterile, freshly hatched $M$. javanica preparasitic J2s. Plates were left uncovered in a laminar flow hood until water had completely soaked into the medium (59). The inoculated and noninoculated roots were left to grow horizontally in the dark and root samples were taken for either RNA extraction or histological studies at the designated time points after inoculation.

Molecular identification of nematode collection. Molecular identifications were performed using diagnostic primers according to Dong et al. (20), Blok et al. (8), and Ziljstra et al. (72). DNA was extracted from individual females from each population according to Castagnone Sereno et al. (15), with the following modifications. Individual females were frozen in liquid nitrogen and ground by mortar and pestle in $100 \mu \mathrm{l}$ of worm lysis buffer, $500 \mathrm{mM} \mathrm{KCl}, 100 \mathrm{mM}$ Tris- $\mathrm{HCl}$ (pH 8.2), $15 \mathrm{mM} \mathrm{MgCl}_{2}, 1 \mathrm{mM}$ dithiothreitol, proteinase $\mathrm{K}$ (Roche Diagnostics, East Sussex, U.K.) at $60 \mu \mathrm{g} \mathrm{ml}{ }^{-1}$, and $4.5 \%$ (vol/vol) Tween 20 and incubated at $65^{\circ} \mathrm{C}$ for $1 \mathrm{~h}$. Proteinase $\mathrm{K}$ was inactivated by incubation at $95^{\circ} \mathrm{C}$ for $10 \mathrm{~min}$ and centrifugation for $10 \mathrm{~min}$ at $5,000 \times g$. The supernatant was transferred to a new tube and $1 / 10$ vol of $3 \mathrm{M}$ sodium acetate, glycogen at 0.05 to $1 \mu \mathrm{g} \mu \mathrm{l}^{-1}$, and $1 \mathrm{vol}$ of isopropanol were added, followed by incubation at $-70^{\circ} \mathrm{C}$ for $30 \mathrm{~min}$ and then centrifugation for $15 \mathrm{~min}$ at $10,000 \times \mathrm{g}$. Precipitated genomic DNA was washed with $70 \%$ cold ethanol and resuspended in $30 \mu \mathrm{l}$ of ultrapure water. The supernatantextracted DNA from each individual female was used as a template to amplify the intergenic spacer between the $5 \mathrm{~S}$ and $18 \mathrm{~S}$ ribosomal genes using primers 194/195, as described by Blok et al. (8), to confirm their belonging to the Meloidogyne group. In addition, we used the species-specific SCAR primers Finc/Rinc to identify $M$. incognita (55) and Fhap/Rhap and Fjav/Rjav primer pairs to identify $M$. hapla and $M$. javanica, respectively (20). For controls, DNA was extracted from $M$. javanica-, $M$. incognita-, and $M$. hapla-reared populations, which were verified by perineal patterns of 10 egg-laying females of each that were prepared according to Taylor and Netscher (63) and Hartman and Sasser (27).

Extracted DNA was immediately transferred to a $25-\mu \mathrm{l}$ PCR amplification mixture containing $0.8 \mu \mathrm{M}$ each primer pair, $2 \mathrm{mM}$ $\mathrm{MgCl}_{2}, 200 \mu \mathrm{M} \mathrm{dNTP}, 1 \times$ PCR buffer, and $1 \mathrm{U}$ of Taq polymerase in a $0.2-\mathrm{ml}$ microcentrifuge tube placed on ice. Samples were placed into the Biometra T3 thermocycler PCR machine. The amplification program included a denaturation step of $3 \mathrm{~min}$ at $94^{\circ} \mathrm{C}$ followed by 45 cycles of $1 \mathrm{~min}$ at $94^{\circ} \mathrm{C}, 45 \mathrm{~s}$ at $48^{\circ} \mathrm{C}$, and $2 \mathrm{~min}$ at $70^{\circ} \mathrm{C}$. The last cycle was followed by $5 \mathrm{~min}$ at $72^{\circ} \mathrm{C}$ to complete the extension of any partially synthesized second strands. All PCR amplification products were electrophoresed through a $1 \%$ agarose gel in $1 \times$ Tris-acetate-EDTA buffer $(0.04 \mathrm{M}$ Tris-acetate and 0.001 M EDTA, pH 7.8) and visualized by UV illumination after staining with ethidium bromide.

Nematode virulence assay. For the in vivo virulence test, plants were inoculated with 3,500 eggs. After inoculation, plants were maintained at 22 to $25^{\circ} \mathrm{C}$ for 6 weeks, allowing completion of one RKN generation. After this period, plants were uprooted and roots were washed of soil. Root fresh weight was recorded, and eggs were extracted from individual root systems using the bleach and blending method described above. Egg suspensions

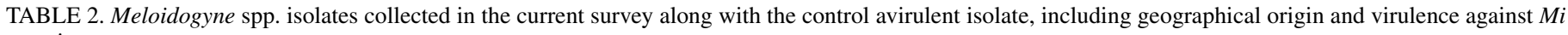
gene in tomato

\begin{tabular}{|c|c|c|c|c|}
\hline Isolate code & Species & Origin in Israel & Host selected & Virulence on $M i$ \\
\hline Mjv1 & Meloidogyne javanica & Hasharon region & $M i$-resistant cultivar & Field selected \\
\hline Mjv2 & M. javanica & North Negev & $M i$-resistant cultivar & Field selected \\
\hline Mjv3 & M. javanica & North Negev & Resistant rootstock & Field selected \\
\hline Mjv4 & M. javanica & Negev Hills & $M i$-resistant cultivar & Field selected \\
\hline Mjv5 & M. javanica & Arava desert & Resistant rootstock & Field selected \\
\hline Mjv6 & M. javanica & North Negev & Resistant rootstock & Field selected \\
\hline Mjv7 & M. javanica & North Negev & Resistant rootstock & Field selected \\
\hline Mjav1 & M. javanica & Hasharon & $\ldots$ & Avirulent \\
\hline
\end{tabular}


were centrifuged and resuspended in $10 \mathrm{ml}$ of double-distilled $\mathrm{H}_{2} \mathrm{O}$ before counting. After appropriate dilution, eggs in 5- $\mu$ l aliquots from each sample were counted using a dissecting scope, and the number of eggs per root system was calculated. Each combination of host genotype and nematode isolate was replicated 15 times. Plants were arranged in a randomized complete block design, each block including five plants from each of the 14 nematode-genotype combinations tested. Data were then analyzed by means of a two-way analysis of variance using the tomato genotypes, the nematode isolates, and their interaction as the tested effects and the number of eggs per gram of root as the dependent variable. Tukey-Kramer's multiple-comparison test was used to determine the significance of mean differences among tomato genotype-nematode isolate combinations. All statistical analyses were performed using JMP 5.0.1j computer software (SAS Institute, Tokyo, Japan). The whole experiment was repeated three times, and a representative data set is shown.

Histological analysis of giant-cell development. To monitor the development of nematode isolates on the three genetic backgrounds ( $\mathrm{Mi} / \mathrm{Mi}, \mathrm{Mi} / \mathrm{mi}$, and $\mathrm{mi} / \mathrm{mi})$, root systems grown in monoxenic culture were harvested at 15 and 28 days postinfection (dpi). Ten 10-mm-long root tips were harvested randomly from each genotype and immersed in fixative buffer $(0.25 \%$ [ $\mathrm{vol} / \mathrm{vol}]$ glutaraldehyde and $4 \%$ [vol/vol] paraformaldehyde in $50 \mathrm{mM}$ phosphate-buffered saline, $\mathrm{pH}$ 7.2). The roots were left overnight in the fixative at $4^{\circ} \mathrm{C}$, then dehydrated by passing through a graded ethanol series (10 to 100\%). Infiltration and embedding were performed with Technovit 7100 (Heraeus Kulzer, Wehrheim, Germany) according to the manufacturer's instructions. Semithin (4- $\mu$ m-thick) sections were cut using a JB-4 microtome (DuPont Sorvall, Newtown, CT) with triangular glass knives. The sections were stained in $0.5 \%(\mathrm{wt} / \mathrm{vol})$ toluidine blue $\mathrm{O}$ in borate buffer ( $\mathrm{pH} 4.4)$. Digital microscopy was performed using a Leica DMLB light microscope (Leica Microsystems GmbH, Wetzlar, Germany) and images were collected with a digital camera Nikon Eclipse 90i (Nikon Corporation, Tokyo).

The average number of GCs observed at 15 and 28 days postinoculation for 60 gall cross sections of each tomato genotypenematode isolate interaction was calculated. In addition, the average GC area at 15 and 28 days postinoculation was measured on the three biggest GCs of each $50 \mathrm{GC}$ gall cross sections by using the ImageJ 1.46r software (http://imagej.nih.gov/ij).

RNA isolation and quantitative PCR. Gene transcripts were quantified by real-time reverse-transcription (RT)-PCR on total RNA extracted from infected and noninfected roots of the three tomato genotypes differing in $\mathrm{Mi}$ allelic condition (2128, 2129, 2130) at 2 and 5 dpi. We analyzed the expression level of several JA-biosynthesis genes and octadecanoid pathway genes (allene oxide cyclase [AOC], allene oxide synthase 2 [AOS2], and 12-oxophytodienoic acid reductase $3[O P R 3]$ ), the JA pathway woundinducible genes (proteinase inhibitor [PI-1], $\gamma$-thionin, Apsl, vegetative storage protein acid phosphatases [Vsp], and multicystatin $[M C])$. For the ET pathway, expression of the ET biosynthesis genes (S-adenosyl-methionine synthase 2 [SAM2] and 1aminocyclopropane-1-carboxylic oxidase 1 [ACO1]) was analyzed. In addition, a marker gene for the SA-dependent response (pathogenesis-related gene $[P R-1])$ and a key biosynthesis enzyme in the SA pathway, phenylalanine ammonia lyase 5 (PAL5), were examined to evaluate the degree of change in gene expression following inoculation with avirulent and $M i$-virulent isolates. Two biological replicates, each composed of a pool of six individual roots, were taken. Prior to all RNA extractions, samples were mechanically disrupted and homogenized using glass beads and liquid nitrogen. RNA was then extracted from the homogenized samples using the InviTrap Spin Plant RNA Mini Kit (Invitek, Berlin). To remove contaminating genomic DNA, RNA samples were incubated in the presence of $10 \mathrm{U}$ of TURBO DNA-free DNASE (Applied Biosystems, Foster City, CA). DNA-free RNA was converted into first-strand cDNA using the Verso cDNA Synthesis Kit (ABgene, Epsom, UK) and quantitative (q)RT-PCR was performed using the SYBR-Green ROX Mix (ABgene). qRTPCR primers were designed using Primer Express software (Applied Biosystems) (Supplemental Table 2). The subsequent real-time PCR contained $3.4 \mu \mathrm{l}$ of the cDNA in a total volume of $10 \mu \mathrm{l}$, consisting of $1 \times$ SYBR-Green ROX Mix (ABgene), 150 $\mathrm{nM}$ forward primer, and $150 \mathrm{nM}$ reverse primer in real-time PCR plasticware (Axygen, Union City, CA). All PCR cycles began with $2 \mathrm{~min}$ at $50^{\circ} \mathrm{C}$, then $10 \mathrm{~min}$ at $95^{\circ} \mathrm{C}$, followed by 40 two-step cycles comprising $10 \mathrm{~s}$ at $95^{\circ} \mathrm{C}$ and $1 \mathrm{~min}$ at $60^{\circ} \mathrm{C}$. After the PCR, a melting curve was generated by gradually increasing the temperature to $95^{\circ} \mathrm{C}$ to test for amplicon specificity. For qPCR, a mixture of all cDNAs was used for all treatments, as a template for calibration curves designed for each pair of primers. Each reaction was performed in triplicate and the results represent the mean of two independent biological experiments. Three constitutively expressed genes-actin (ACT; GenBank accession number U60482.1), $\beta$-tubulin (TUB; GenBank accession number NM_001247878.1), and $18 S$ (GenBank accession number BH012957.1) - were used as endogenous controls for tomato gene-expression analysis. Transcript levels were normalized for each sample with the geometric mean of the corresponding selected housekeeping genes. All of the housekeeping genes were confirmed to display minimal variation across the treatment and were the most stable of a set of tested genes in a given cDNA sample. The control reactions were included as follows: PCR negative control without cDNA template to confirm that there were no nonspecific PCR products, and a second reaction containing mRNA that had not been subjected to RT reaction. Statistical differences between treatments or root lines were calculated by least significant difference, according to a TukeyKramer multiple comparison test at $P \leq 0.05$. For confirmation of all qRT-PCR results, expression of the subset of genes was analyzed in another two independent experiments, producing the same results.

\section{RESULTS}

Occurrence of selected Meloidogyne spp. isolates naturally virulent against the resistance gene $M i$ in Israel. A nematode survey was carried out in the main Israeli greenhouse tomatoproduction areas - the Arava region, northern Negev, Negev Hills, and Hasharon region-which had been cultivated with resistant tomato genotypes (commercial cultivars or rootstocks) for the last 2 years. To confirm isolate virulence against the $M i$ gene, all naturally selected isolates were tested for their reproduction on Avigail $870(\mathrm{mi} / \mathrm{mi})$ and Sherlot $1402(\mathrm{Mi} / \mathrm{mi})$ tomato in a pot experiment under controlled conditions; from these, seven representative single egg mass isolates were chosen for further characterization. The seven isolates were then propagated over three successive generations on resistant Sherlot 1402 and susceptible Avigail 870, indicating that none of the selected isolates had lost the ability to overcome the resistance gene $M i$. Details on the origin of the nematode isolates collected throughout this study and their virulence against tomato containing the $M i$ gene are listed in Table 2. For nematode isolate identification using molecular markers, females from single-egg-mass lines of $M$. incognita, M. javanica, and M. hapla, which had been previously identified by perineal pattern, were used as controls. Isolates were identified based on the general primers for Meloidogyne spp. 194/195 (8) and the species-specific SCAR primers Finc/Rinc for $M$. incognita (72) and Fhap/Rhap and Fjav/Rjav for M. hapla and $M$. javanica, respectively (20). All primers used for genus and species-specific identification are listed in Supplemental Table 1. The 720-bp amplification product of the primer pair 194/195 was obtained from the seven selected populations, confirming that they all belong to the genus Meloidogyne (Fig. 1A). In addition, 
all collected isolates gave a positive PCR product of $1,650 \mathrm{bp}$ with the primer pair Fjav/Rjav (Fig. 1B), showing that they belong to $M$. javanica, whereas no positive signal was detected with the $M$. incognita or $M$. hapla primer pairs, except for the respective control samples (Fig. $1 \mathrm{C}$ and D). These results indicated that the selected $M i$-virulent isolates tested throughout this study were all $M$. javanica (Fig. 1).

Impact of increasing number of $\mathrm{Mi}$ alleles and genetic background on reproduction of local avirulent and $\mathrm{Mi}$-virulent RKN isolates. To evaluate the impact of allelic condition and genetic background on the reproduction of avirulent and virulent isolates, five fixed susceptible lines $(\mathrm{mi} / \mathrm{mi})$, four $\mathrm{F}_{1}$ hybrids heterozygous for $\mathrm{Mi}(\mathrm{Mi} / \mathrm{mi})$, and five fixed lines homozygous for $M i(M i / M i)$ with different genetic backgrounds (as detailed in Table 1) were assayed for their response to avirulent and virulent nematodes at 6 weeks postinfection (Fig. 2). Prior to inoculation, all tomato genotypes were reconfirmed for their $M i$ allelic condition using a PCR-based method $(22,57,69)$. Reproduction of the avirulent isolate Mjav1 on the susceptible genotypes ( $\mathrm{mi} / \mathrm{mi}$ ), measured as eggs per gram of root, exhibited high variation, ranging, on average, from 8,060 \pm 454 ( \pm standard deviation [SD]) to 22,296 $\pm 12,592( \pm \mathrm{SD})$ eggs/g of root tissue (Fig. 2A); the different genetic backgrounds, as detailed in Table 1, might have contributed to this variation. To evaluate the resistance response of tomato genotypes carrying the $M i$ allele against avirulent isolates, $M i$-heterozygous and -homozygous lines were inoculated and assessed for disease development (Fig. 2A). Although the $\mathrm{F}_{1}$ hybrid genotypes $(\mathrm{Mi} / \mathrm{mi})$ are considered resistant to avirulent isolates, the appearance of Mjav1 J2s that did develop into fertile females led to a significantly lower level of egg production of, on average, 0 to $399 \pm 167( \pm \mathrm{SD})$ eggs/g of root tissue (Fig. 2A). This low reproduction of the avirulent isolate was observed on both heterozygous $F_{1}$ hybrids - 2130 and $\mathrm{V}$-1059 - carrying one $M i$ allele but not on the heterozygous line $\mathrm{V}-2034$. These results suggest that the avirulent isolates are able to reproduce on certain genetic backgrounds carrying one $\mathrm{Mi}$ allele within a single generation, illustrating the potential of avirulent isolates to overcome the resistance gene $M i$ under these conditions. Nevertheless, analyzing the response of the fixed homozygous $M i$ lines to the avirulent isolate showed, as expected, significantly lower RKN reproduction compared with some of the heterozygous lines, indicating a highly resistant phenotype con- ferred by all genetic backgrounds carrying two $M i$ alleles (Fig. 2A). These findings indicated that the $M i$-dosage effect along with additional factors derived from the genetic background might act as determinants in disease development against avirulent isolates of $M$. javanica (Fig. 2A). The interaction of the same tomato genotypes was then tested with the $M i$-virulent isolate Mjv2, which was naturally selected on resistant tomato plants (Table 2; Fig. 1). The virulent nematodes reproduced well on all susceptible and resistant genotypes (heterozygous or homozygous for the $M i$ gene) (Fig. 2B), confirming the high virulence of $M$. javanica isolate Mjv2 toward the resistance gene $M i$. The $M i$ virulent isolate showed high reproduction on the susceptible genotypes $(\mathrm{mi} / \mathrm{mi})$, with $>8,635 \pm 3,565( \pm \mathrm{SD})$ eggs/g of root tissue (Fig. 2B). Similarly, the $M i$-virulent isolate showed a high rate of reproduction on both heterozygous and $\mathrm{Mi}$-homozygous genotypes, reaching $6,043 \pm 3,073( \pm \mathrm{SD})$ and 16,366 $\pm 5,221$ $( \pm \mathrm{SD})$ eggs/g of root tissue, respectively (Fig. 2B). These results indicated that reproduction of the local $M i$-virulent isolate is not affected by allelic condition. Although the genetic background of homozygous resistant genotypes had no effect on reproduction of the avirulent $M$. javanica isolate, a significant influence of genetic background was observed among some of the susceptible and heterozygous ( $\mathrm{mi} / \mathrm{mi}, \mathrm{Mi} / \mathrm{mi})$ genotypes infested with avirulent nematodes. Similarly, a significant effect of genetic background was observed within each group of susceptible $(\mathrm{mi} / \mathrm{mi})$ and resistant $(\mathrm{Mi} / \mathrm{mi}$ and $\mathrm{Mi} / \mathrm{Mi})$ genotypes infected with the $\mathrm{Mi}$ virulent isolate.

Histological response of tomato genotypes to avirulent and $M i$-virulent RKN isolates. To further characterize the avirulent and selected $M i$-virulent isolates' behavior, histological analysis of infected root tissues of susceptible line $2128(\mathrm{mi} / \mathrm{mi})$ and resistant lines $2130(\mathrm{Mi} / \mathrm{mi})$ and $2129(\mathrm{Mi} / \mathrm{Mi})$ inoculated with avirulent or virulent isolates Mjav1 or Mjv2, respectively, was performed. Sterile tomato root cultures of each line were inoculated with 250 sterile infective J2s and sections of roots were examined, comparing nematode developmental stages and giantcell (GC) systems at two different time points (15 and $28 \mathrm{dpi}$ ). Healthy GC complexes containing dense cytoplasm were similarly induced by both avirulent and $M i$-virulent nematodes on the susceptible genotype $(\mathrm{mi} / \mathrm{mi})$ at both time points. These GCs were irregular in shape and tended to be elongated or rounded, demonstrating similar dimensions (Figs. 3A and D and 4A and D).

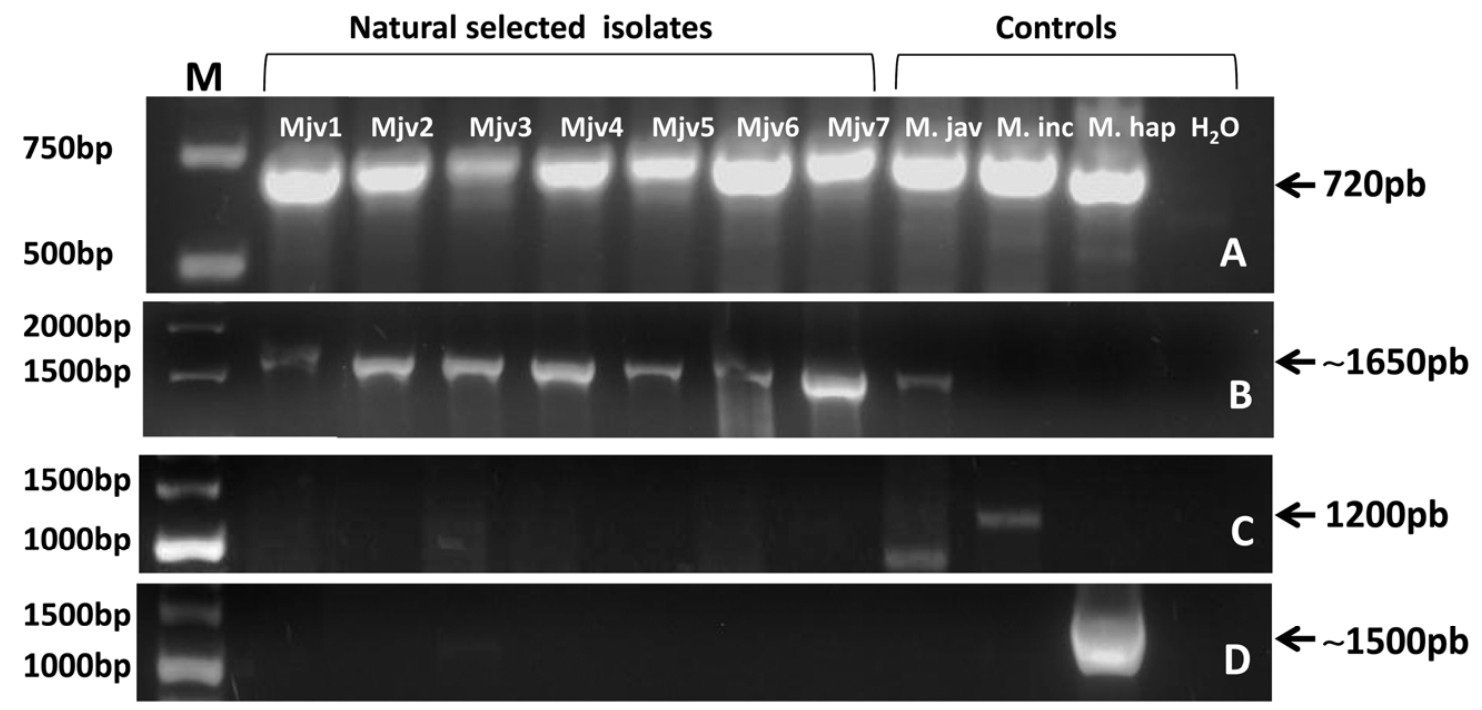

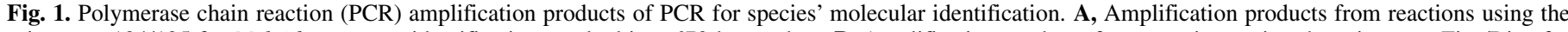



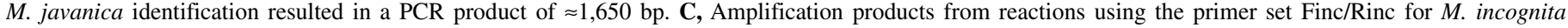

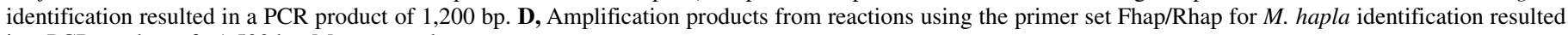
in a $P C R$ product of $\approx 1,500 \mathrm{bp}$. $\mathrm{M}=$ gene ruler. 
Similar to previous observations, avirulent nematodes penetrated the roots of plants carrying the $M i$ gene and those of susceptible plants in a similar manner (Figs. $3 \mathrm{~B}$ and $\mathrm{C}$ and $4 \mathrm{~B}$ and $\mathrm{C}$ ), and managed to reproduce poorly on the heterozygous $\mathrm{F}_{1}$ hybrids (Fig. 2). By histological analysis, the GCs induced on the Mi/mi heterozygous line by the avirulent isolate seemed smaller in average size than those induced by the avirulent isolate on the susceptible line, as observed at 15 and 28 dpi (Figs. 3A, B, H, and $\mathrm{G}$; and $4 \mathrm{~A}, \mathrm{~B}, \mathrm{H}$, and $\mathrm{G}$ ). These observations might support the low number of nematodes that managed to fully reproduce on the heterozygous line (i.e., fully develop and reach maturity to lay eggs) (Fig. 2A). Analysis of the interaction of avirulent isolates on the $M i$-homozygous line indicated that, in a few cases, the nematodes survived for a while and induced GCs; the apparently empty regions which were often associated with the cytoplasm of these GCs (Fig. 4C) might contribute to the poor larval development usually associated with these cells (Figs. 3C and 4C). The selected $M i$-virulent isolate Mjv2 induced well-developed GCs containing uniformly dense cytoplasm, numerous large nuclei, and thickened walls on all three tomato genotypes ( $\mathrm{mi} / \mathrm{mi} 2128$, $\mathrm{Mi} / \mathrm{mi}$ 2130, and $\mathrm{Mi} / \mathrm{Mi} 2129$ ), as observed at 15 and 28 dpi (Figs. $3 \mathrm{D}$ to $\mathrm{F}$ and $4 \mathrm{D}$ to $\mathrm{F}$ ). This acute histological response, in which a group of GCs consisting of many clusters was observed on all three genotypes, illustrates the concrete threat in the occurrence of selected $M i$-virulent isolates.

Systemic JA/ET- and SA-related responses upon inoculation with avirulent and $M i$-virulent isolates. To gain insight into the systemic response of tomato genotypes differing in $\mathrm{Mi}$-allelic condition upon inoculation with avirulent versus $M i$-virulent isolates, the differential expression of genes involved in JA/ET and SA pathways was investigated using qRT-PCR. For a timecourse analysis, systemic tissues of the three genotypessusceptible $(2128 \mathrm{mi} / \mathrm{mi})$, heterozygous $(2130 \mathrm{Mi} / \mathrm{mi})$, and homozygous $(2129 \mathrm{Mi} / \mathrm{Mi})$-were collected at two time points after inoculation ( 2 and $5 \mathrm{dpi}$ ). As controls, noninfected roots from plants grown in parallel with and under identical conditions as the inoculated plants were taken. Key biosynthesis and hormone-responsive genes were chosen for the JA/ET and SA pathways and their differential expression was evaluated upon nematode infection. The differential expression of nine important defense-related genes in systemic tissues in comparison with reference material from noninoculated plants of the respective genotypes $(\mathrm{mi} / \mathrm{mi}, \mathrm{Mi} / \mathrm{mi}$, and $\mathrm{Mi} / \mathrm{Mi})$ is shown in Figures 5, 6, and 7. Comparing the relative expression of each target gene in
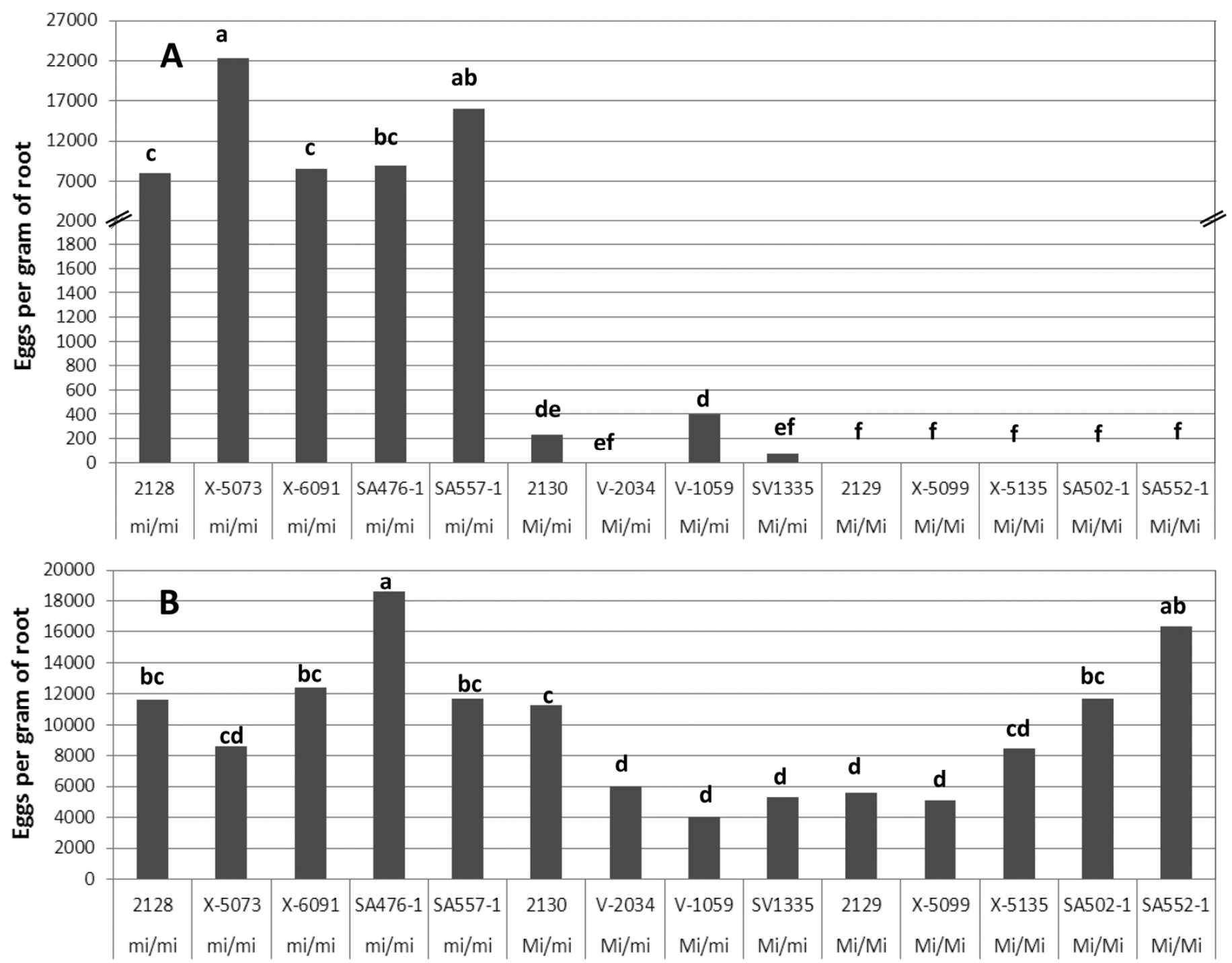

Fig. 2. Reproduction of avirulent and Mi-virulent Meloidogyne javanica isolates on tomato genotypes differing in $M i$ allelic condition and genetic background. Average number of eggs per gram of root of $\mathbf{A}$, avirulent or $\mathbf{B}, M i$-virulent isolates produced on susceptible tomato ( $\mathrm{mi} / \mathrm{mi}$ ), or tomato homozygous ( $\mathrm{Mi} / \mathrm{Mi})$ or heterozygous $(\mathrm{Mi} / \mathrm{mi})$ for the resistance gene $\mathrm{Mi}$. Tomato genotypes are described in more detail in Table 1. Disease evaluation and egg extraction were conducted at 6 weeks postinoculation, allowing for the completion of one root-knot nematode generation. Different letters above the bars denote significant differences $(P \leq$ 0.05 , analysis of variance) between tomato genotypes analyzed by Tukey-Kramer multiple comparison tests. 
the three genotypes indicated that, following inoculation of the susceptible line $(2128 \mathrm{mi} / \mathrm{mi})$ with avirulent (Mjav1), there was a significant increase in the expression of the JA-biosynthesis genes $A O S$ and $O P R 3$ at 5 dpi (Fig. 5), and a significant increase of $O P R 3$ following inoculation with the $M i$-virulent (Mjv2) isolates (Fig. 5). In addition, this expression analysis was followed by increased expression of JA-inducible genes PI-1, $\gamma$-thionin, and Aps1 at 5 dpi (Fig. 6). These findings suggest that this pathway is induced by both avirulent and $M i$-virulent invading nematodes and might be associated with nematode establishment in the roots. The measured response of the heterozygous $(\mathrm{Mi} / \mathrm{mi})$ genotype indicated significant upregulation of $A O S$ and $A O C$ expression as early as $48 \mathrm{~h}$ postinfection and $5 \mathrm{dpi}$, respectively, by both avirulent and $M i$-virulent isolates, followed by an increase in the expression of JA-responsive genes observed mainly at 5 dpi. On the other hand, in the homozygous line $\mathrm{Mi} / \mathrm{Mi}$, the JA-biosynthesis genes (AOS, AOC, and OPR3) did not show differential expression upon inoculation with the avirulent isolate Mjav1, and the JA-responsive gene transcripts showed only a moderate increase. Nevertheless, significant upregulation of JA-biosynthesis and JA-inducible genes was evident following infection with the $M i$-virulent isolate, suggesting that this pathway is associated with the susceptibility response observed in the $M i$-homozygous line inoculated with $M i$-virulent isolates. Monitoring marker genes for the SA-dependent response through PAL5 and PR-1 showed significant induction of the latter in the susceptible ( $\mathrm{mi} / \mathrm{mi}$ ) line $5 \mathrm{dpi}$ with the avirulent and virulent isolates. $P R-1$ upregulation was also significant in the heterozygous $(\mathrm{Mi} / \mathrm{mi})$ genotypes as early as 2 dpi (Fig. 7). Following interaction of the avirulent isolate with the $(\mathrm{Mi})$-homozygous line, no expression of $P R-1$ was observed. However, the systemic transcript level of
PAL5 was hardly expressed upon RKN infection but, rather, showed some minor downregulation at $2 \mathrm{dpi}$ in association with a compatible interaction of the $\mathrm{mi} / \mathrm{mi}$ genotype with avirulent and virulent isolates or of the heterozygous genotype with the virulent isolate (Fig. 7). To analyze the systemic ET-related responses upon nematode infection, expression of ET-biosynthesis-related genes $S A M 2$ and $A C O 1$ was examined to evaluate the degree of change in gene expression upon susceptible or resistant interactions. Our experiments revealed slight but consistent upregulation of $S A M 2$ in systemic root tissues where nematode reproduction was observed, whereas there was no change upon inoculation of the $(\mathrm{Mi})$ homozygous genotype with the avirulent isolate. On the other hand, the ACOl gene only showed clear upregulation in roots carrying $M i$, whereas only a minor change was observed in the non-Mi-carrying plants following inoculation with both isolates (Fig. 7).

\section{DISCUSSION}

A high frequency of emergence of $M i$-virulent nematode populations on resistant tomato cultivars in Israel is a major concern for tomato production in agriculture. Given that soil infested with virulent isolates could significantly reduce the durability of the resistance gene $\mathrm{Mi}$, it is important to understand the determinants leading to possible resistance failure. The purpose of the current study was to (i) conduct an initial characterization of selected $M i$-virulent isolates occurring naturally in tomato-production greenhouses in Israel, (ii) highlight the impact of $M i$ allelic condition and genetic background on resistance failure following interaction with avirulent and virulent isolates, and (iii) elucidate the mechanism underlying the tomato
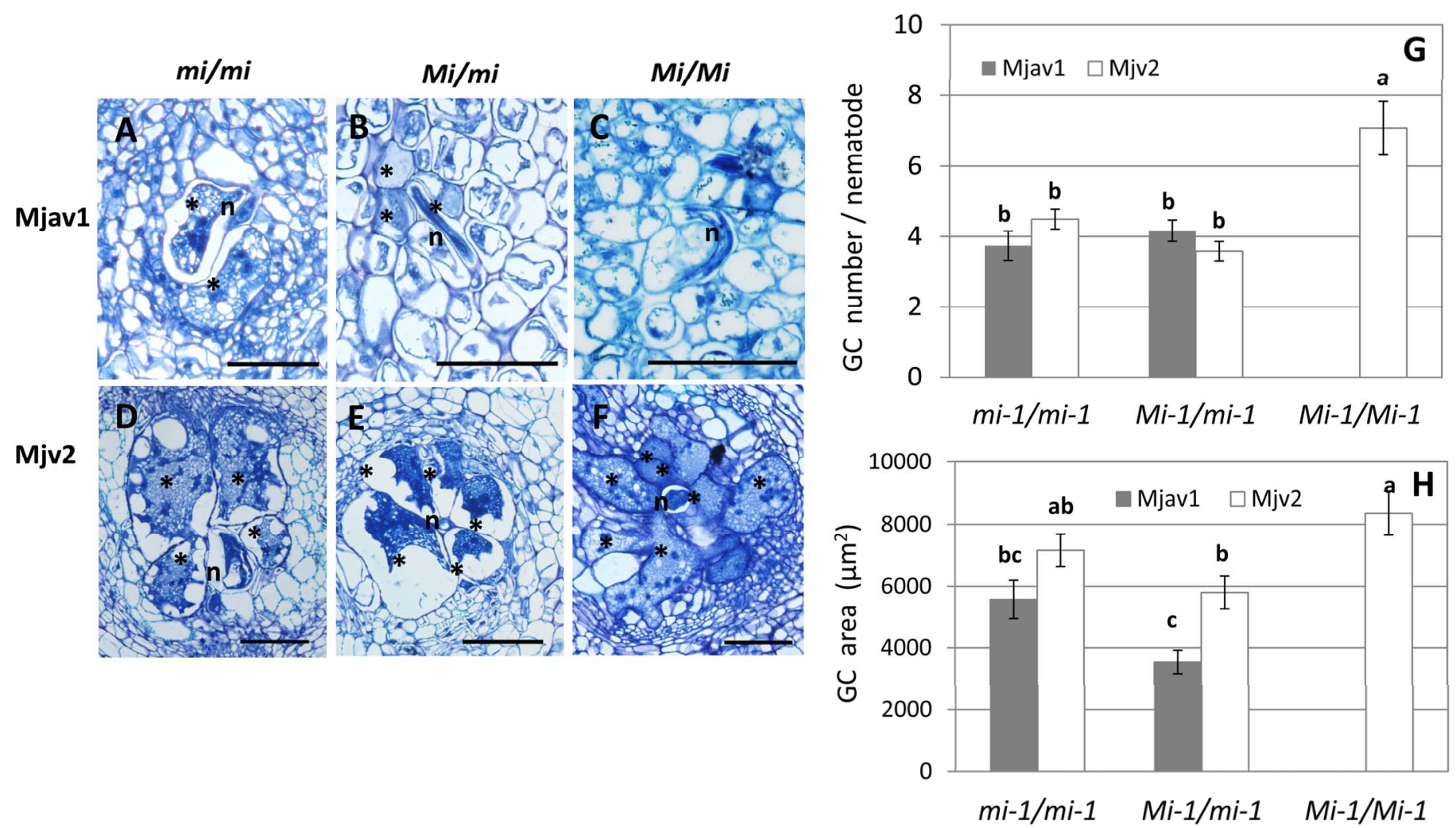

Fig. 3. Longitudinal sections of Meloidogyne javanica feeding sites induced by avirulent and Mi-virulent isolates 15 days postinoculation. Histological analysis of the three different genotypes: A, $\mathrm{mi} / \mathrm{mi} ; \mathbf{B}, \mathrm{Mi} / \mathrm{mi}$; and $\mathbf{C}, \mathrm{Mi} / \mathrm{Mi}$ inoculated with avirulent isolate. Histological analysis of the three different genotypes: $\mathbf{D}$, mi/mi; E, $M i / m i$; and $\mathbf{F}, M i / M i$ inoculated with $M i$-virulent isolate. At 15 days postinoculation, giant-cell (GC) systems of plants carrying the $M i$ gene were more developed in roots which were inoculated with $M i$-virulent isolates. Sections were stained with toluidine blue; $*$ GC, $\mathrm{n}=$ nematode, bar $=100 \mu \mathrm{m}$. $\mathbf{G}$, Average number of GCs at 15 days postinoculation of 60 gall cross sections for each tomato genotype-nematode isolate interaction. $\mathbf{H}$, GC area was measured on $50 \mathrm{GC}$ systems. Measurements are given as mean \pm standard error. Different letters above the bars denote statistically significant differences $(P \leq 0.05$, analysis of variance) determined by Tukey-Kramer multiple comparison tests. 
resistance or susceptibility response to local avirulent and $\mathrm{Mi}$ virulent isolates.

Using molecular markers, we demonstrated the predominance of $M$. javanica species among the seven virulent Meloidogyne isolates occurring naturally on resistant cultivars or rootstocks (Fig. 1). Given that all of the tested isolates were collected from tomato-production greenhouses where resistant cultivars are intensively used, we followed a previous convention in terminology for similar isolates $(4,35,47,51-53)$, referring to them as naturally selected virulent isolates because they were presumably induced by selection pressure over the $M i$ gene. In the Mediterranean region, to date, resistance-breaking populations of $M$. javanica have been reported in Cyprus, Crete, Morocco, Tunisia, Spain, and Greece $(21,43,47,49,65,66)$ and of $M$. incognita only in France $(13,34)$ and the United States (California) (28); virulent $M$. javanica isolates have only been identified among the selected $M i$-virulent isolates found in the current survey. Selection for $M$. incognita might be occurring as well, whereas a high frequency of $M$. javanica on tomato in the Mediterranean region (21,31, $38,48,58,66)$ might explain the predominance of virulent $M$. javanica isolates. These findings provide additional records of the occurrence of virulent populations of $M$. javanica in greenhouse tomato-production areas in the Mediterranean region and can be added to the long list of $\mathrm{Mi}$-resistance-breaking populations occurring worldwide. Considering the fact that $M i$-containing tomato has allowed an increased proportion of $M i$-virulent isolates in the overall population in a short period because of their ability to produce viable offspring (28), the characteristics and behavior of these isolates should be studied in depth.

Among the factors affecting resistance performance against avirulent, partially virulent, or virulent isolates, the $M i$ allelic condition (i.e., heterozygous versus homozygous) is frequently raised because it could explain some of the variation observed in nematode reproduction on resistant genotypes $(32,67)$. To test the possible influence of $\mathrm{Mi}$ allelic condition on resistance to local avirulent and $\mathrm{Mi}$-virulent isolates, a collection of tomato genotypes differing in their genetic background and $M i$ allelic condition was assembled and the reproductive capacity of both avirulent and $M i$-virulent nematodes was evaluated on these genotypes (Fig. 2).

Our experiments demonstrated variable responses of the tested genotypes to infection by either avirulent or virulent nematodes (Fig. 2). Moreover, variation in reproductive capacity was also observed among the genetic backgrounds within each allelic condition, following inoculation with either avirulent or virulent nematodes (Fig. 2). Reproduction of avirulent isolates was observed on two of the four heterozygous lines that were tested but not on homozygous lines. However, given that high nematode reproduction was detected for the $M i$-virulent isolate on the heterozygous as well as homozygous genotypes, we suggest that reproduction of virulent isolates is completely not affected by the $M i$ allelic stage.

Previous studies on the role of $M i$ allelic condition on plant response to RKNs have provided diverse findings. For instance, reproduction of avirulent versus virulent $M$. incognita was the same in tomato genotypes carrying the $M i$ gene in either the homozygous or heterozygous condition (9). Different results were shown by Tzortzakakis et al. (67), whereby reproduction of partially virulent isolates was much greater on tomato genotypes heterozygous for $M i$ than on those homozygous for the gene, with no difference in reproduction rate of highly virulent isolates on the respective genotypes, indicating an $M i$-dosage effect on only

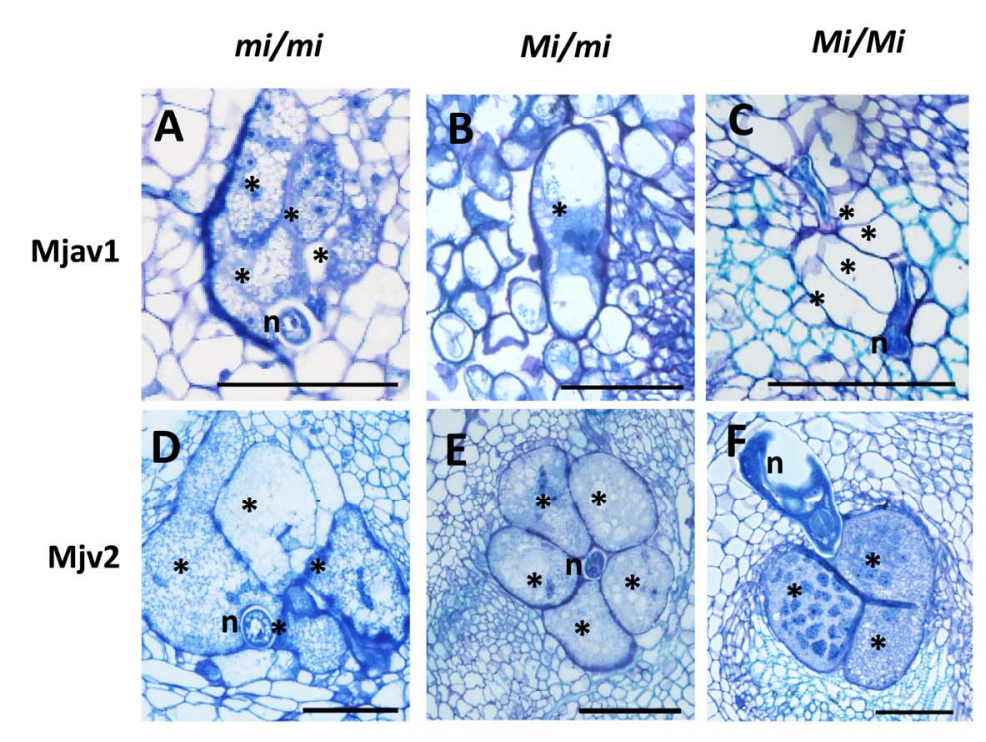


the partially virulent isolate. Later, data obtained with a large number of plant-nematode genotypic relationships (32) showed that $M$. incognita reproduction is significantly higher on $M i$ heterozygous versus homozygous tomato genotypes, suggesting a dosage effect of the $M i$ gene. In this study, the variations observed in nematode reproduction on tomato genotypes heterozygous for $M i$ further illustrate that the genetic background might have a major effect as well on the observed resistance or susceptibility response. Likewise, it could be that, under heterozygous conditions for the $M i$ gene, the genetic background has a greater impact on resistance against avirulent isolates rather than on the homozygous genotypes $(\mathrm{Mi} / \mathrm{Mi})$ inoculated with the same isolate. Taken together with the data presented here, under certain genetic backgrounds and nematode isolates, a dosage effect might be suggested; thus, the ability of some avirulent nematodes to reproduce on heterozygous resistant plants could be a crucial starting point for the development of a virulent population.

Given that the main commercial tomato cultivars are $\mathrm{F}_{1}$ hybrids, with $M i$ in the heterozygous condition, it seems likely that selection for virulent $M$. javanica isolates under field conditions could be promoted on certain heterozygous genotypes. Therefore, using plants carrying two $M i$ alleles, as shown in this study, or pyramiding genes with different resistance mechanisms, as suggested previously by Huang et al. (28), might be important for developing robust sources of resistance.

To further study the parasite's ability to overcome $M i$ resistance in relation to the $M i$ allelic condition, histological analysis of feeding sites induced by both avirulent and virulent isolates was performed. Compatible interactions of RKNs with their host plants require the establishment of feeding sites (i.e., GCs) which provide nutrients and allow the development and reproduction of the parasite (56). Previous studies of the resistance gene $M i$ indicate that $\mathrm{Mi}$-1-mediated defense responses to nematodes are associated with induction of the HR, which prevents GC formation and, therefore, blocks the parasitic life cycle (5). Our results showed that GCs induced on susceptible roots $(\mathrm{mi} / \mathrm{mi})$ by either $M i$-avirulent or -virulent isolates are characterized by dense cytoplasm and seem to have high metabolic activity (Figs. 3 and 4). Our observation of the GCs induced on the heterozygous line by the avirulent isolate are in accordance with the in vivo infec-



Fig. 5. Expression of jasmonate (JA)-biosynthesis genes induced on tomato genotypes by avirulent and $M i$-virulent isolates. Transcript levels of JA-biosynthesis genes $A O S, A O C$, and $O P R 3$ in tomato roots of susceptible $(\mathrm{mi} / \mathrm{mi})$, heterozygous $(\mathrm{Mi} / \mathrm{mi})$, and homozygous $(\mathrm{Mi} / \mathrm{Mi})$ genotypes after inoculation with avirulent or $M i$-virulent isolates of Meloidogyne javanica. Two biological replicates were taken and three independent quantitative reverse-transcription polymerase chain reactions were performed per sample. The graph shows the mean and standard error of the relative amount of transcript of these genes in infected plants in comparison with uninfected control tissue of the respective genotype grown under the same conditions (control expression level set at zero). All target genes were normalized using the normalization factor calculated as the geometric mean of the expression levels of three endogenous reference tomato genes-18S, actin, and $\beta$-tubulin. Statistical significance of the differences between infected plants and control tissue from uninfected plants was determined by Tukey-Kramer multiple comparison test, and significant differential expression $(P \leq 0.05)$ is indicated with asterisks. Experiments were repeated three times with similar results. 
tion test and further support the ability of a few avirulent nematodes to reproduce on $M i$-heterozygous genotypes within a short period. These phenomena, in which nematodes reproduce successfully on heterozygous plants, have also been reported by Jacquet et al. (32) and further illustrate the fragile resistance conferred by only one $M i$ allele. This repeated reproduction on the heterozygous but not on the homozygous genotypes that was observed on two of the four heterozygous genotypes suggests that the condition in which one $M i$ allele is involved might support the occurrence of resistance-breaking isolates. However, the high variation in reproduction of the avirulent isolate observed on the heterozygous lines illustrate a very limited effect.

Consistent with previous studies, $M i$-virulent isolates exhibited a high infestation frequency on all tomato genotypes tested, regardless of their $M i$ allelic condition, as indicated by welldeveloped GC systems which support nematode development and reproduction. Although we did not evaluate the reproduction of the rest of the selected natural $M i$-virulent isolates on all tested genotypes, their reproduction on resistance plants through three successive generations suggests a common behavior of these isolates on $M i$ carrying plants. Nevertheless, previous findings demonstrated considerable differences in reproduction rate among $M i$-virulent nematodes $(28,32,67)$.

Taken together, these results raise some doubt as to the strength of the $M i$-dosage effect against infestation by $M i$-virulent isolates. Given that our results indicate high variation in the capacity of the avirulent and $\mathrm{Mi}$-virulent isolates to reproduce on tomato genotypes carrying the $M i$ gene, we sought the genes that are involved in overcoming the resistance gene $M i$. We examined three hormonal pathways that are known to be involved in plant defense-SA, JA, and ET $(18,23,68)$ - and their systemic response upon nematode infection of tomato. Among the defense-related genes, the JA-biosynthesis genes $A O S$ and $O P R 3$ and JA-inducible genes PI-1, thionin, and Aps 1 were similarly upregulated in the susceptible genotype $(\mathrm{mi} / \mathrm{mi})$ following inoculation with avirulent and $M i$-virulent isolates. Interestingly, the low proportion of avirulent

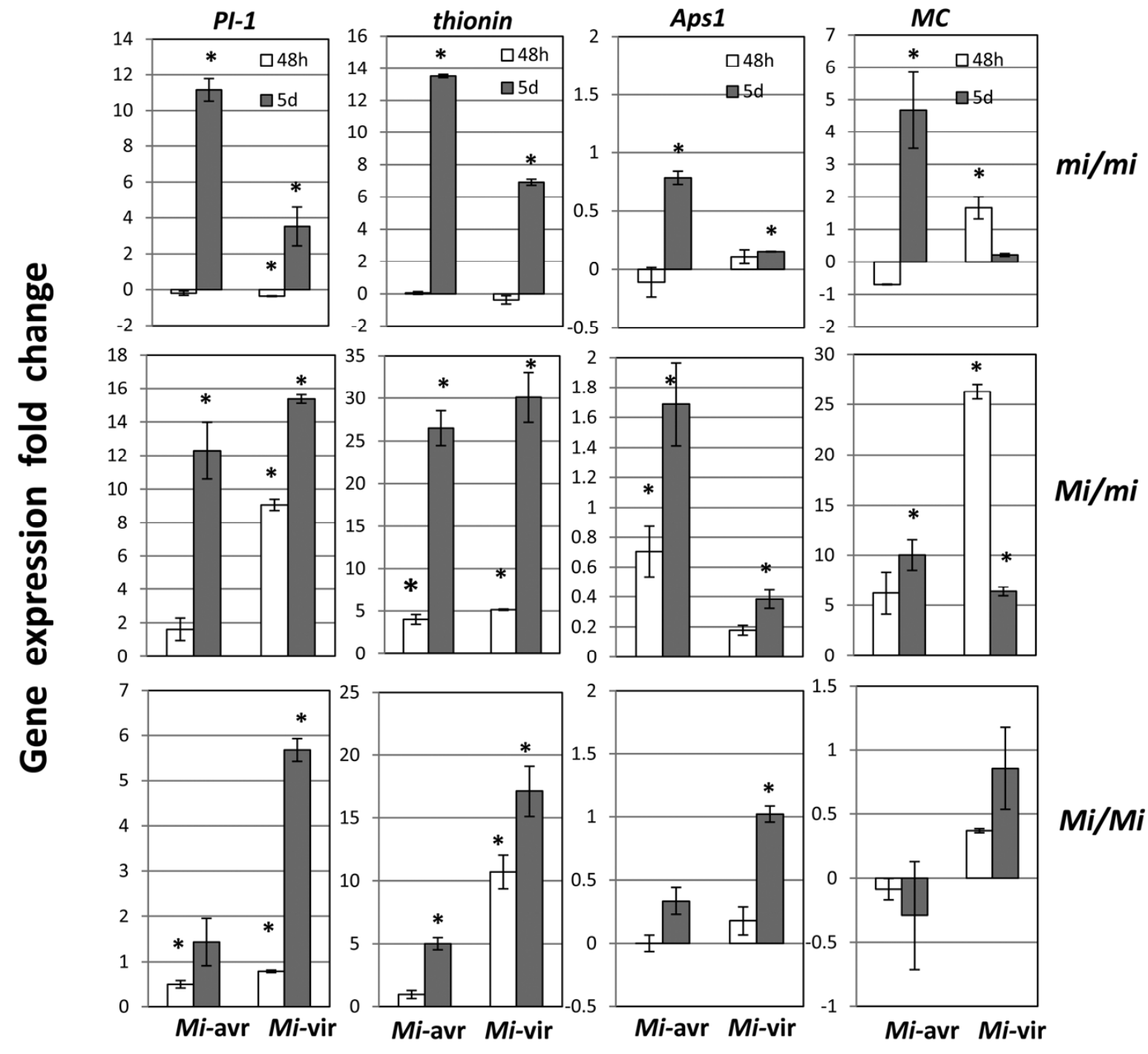

$\mathrm{JA}$ inducible genes

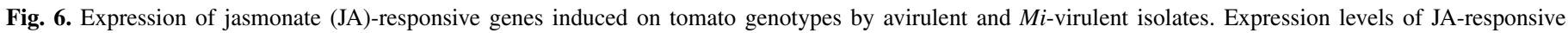

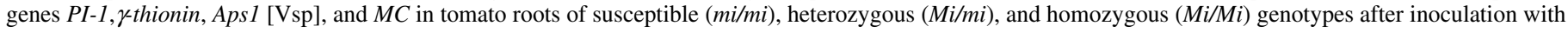

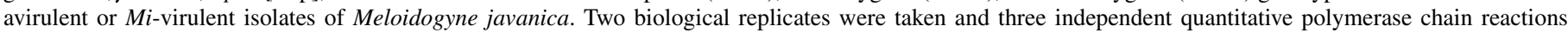

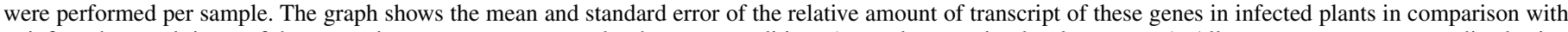

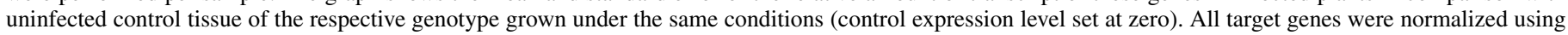

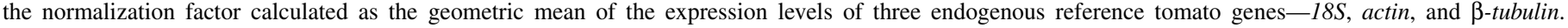

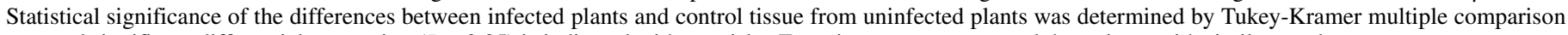
test, and significant differential expression $(P \leq 0.05)$ is indicated with asterisks. Experiments were repeated three times with similar results. 
nematodes that did develop on the heterozygous line induced an earlier response of the JA-biosynthesis gene $A O S$ and a late response of $A O C$ (Fig. 5), whereas no induction of the JA pathway was detected following inoculation of the homozygous $(\mathrm{Mi} / \mathrm{Mi})$ line with the avirulent isolate. These results suggest that, in compatible interactions with either the avirulent or $M i$-virulent isolate, activation of JA-responsive genes by RKNs might reflect the nematode's ability to manipulate plant-defense responses to its advantage by, for example, leveraging the existing crosstalk between JA- and SA-signaling pathways $(10,54)$. Earlier studies have shown that nematode infection activates $P R$ genes during compatible interactions $(3,25,37)$. In agreement with these findings, our study indicated $P R$ induction in all interactions in which nematode reproduction was observed, showing that the root defense system responds to nematode infection, whereas no induction was observed following inoculation of the homozygous line, where full resistance was achieved (Fig. 5). As opposed to $P R, P A L 5$, a SA-biosynthesis gene, showed slight downregulation in susceptible $(\mathrm{mi} / \mathrm{mi})$ roots upon interaction with avirulent and
$M i$-virulent isolates, as well as in heterozygous roots upon interaction with the $M i$-virulent isolate (Fig. 7). These results are in accordance with previous findings demonstrating that negative crosstalk may occur between the JA- and SA-signaling pathways (26). Although RKNs have been shown to actively suppress the ET pathway in both local $(2,36)$ and systemic (44) tissue, in our experiments, changes in $S A M 2$ and $A C O 1$ were variable. In all infestations, $S A M 2$ increased in response to RKN infection, except for the resistance interaction of the avirulent isolate with the (Mi-) homozygous line. These results are in good accordance with previous results shown by Fujimoto et al. (23), where SAM2 has been shown to be a good marker gene for the combined effect of JA and nematode colonization.

ACO1 was hardly expressed in the susceptible genotype following infection with either the avirulent or virulent isolate, whereas it was strongly increased in all genotypes carrying the $M i$ gene. Although most gene upregulation seems to be induced through the establishment of a nematode feeding site $(3,5,50)$, our latest extraction time point at $5 \mathrm{dpi}$, along with RNA extracted from the
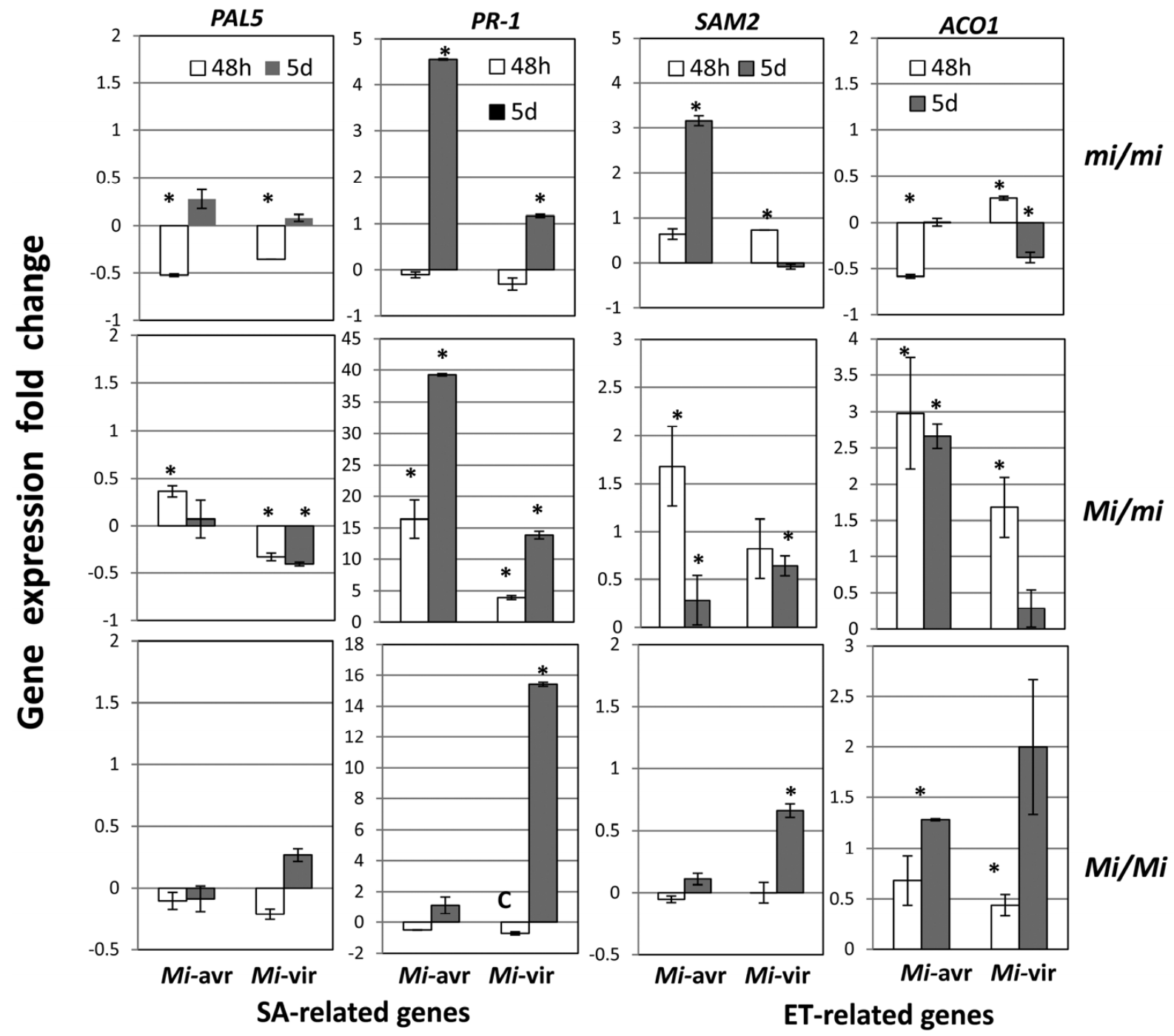

Fig. 7. Expression of salicylic acid (SA)- and ethylene (ET)-related genes induced on tomato genotypes by avirulent and $M i$-virulent isolates. Transcript levels of SA-biosynthesis gene PAL5, SA-responsive gene PR-1, and ET-biosynthesis genes SAM2 and ACO1 were evaluated in tomato roots of susceptible (mi/mi), heterozygous $(\mathrm{Mi} / \mathrm{mi})$, and homozygous (Mi/Mi) genotypes after inoculation with avirulent or Mi-virulent isolates of Meloidogyne javanica. Two biological replicates were taken and three independent quantitative polymerase chain reactions were performed per sample. The graph shows the mean and standard error of the relative amount of transcript of these genes in infected plants in comparison with uninfected control tissue of the respective genotype grown under the same conditions (control expression level set at zero). All target genes were normalized using the normalization factor calculated as the geometric mean of the expression levels of three endogenous reference tomato genes-18S, actin, and $\beta$-tubulin. Statistical significance of the differences between infected plants and control tissue from uninfected plants was determined by Tukey-Kramer multiple comparison test, and significant differential expression $(P \leq 0.05)$ is indicated with asterisks. Experiments were repeated three times with similar results. 
entire root, might not have been evaluating gene expression in the feeding site per se.

In summary, our results indicate, for the first time, the occurrence of highly $M i$-virulent RKN populations, naturally selected in tomato-growing areas of Israel, where the $M i$ gene is intensively used. Given that avirulent isolates successfully reproduced on some of the heterozygous but not on homozygous lines, the selection for virulence could be rapidly established in the field and, thus, threaten the maintenance of the $M i$ resistance gene. Histological analysis along with expression analysis of the defense pathway underlying both interactions indicated that $\mathrm{Mi}$ virulent isolates behave like avirulent isolates on susceptible plants. The overall genetic factors that allow resistance failure should be further investigated.

\section{ACKNOWLEDGMENTS}

This work was financially supported by a grant from the Israeli Ministry of Agriculture and Rural Development (grant number 131-167812).

\section{LITERATURE CITED}

1. Ammati, M., Thomason, I. J., and McKinney, H. E. 1986. Retention of resistance to Meloidogyne incognita in Lycopersicon genotypes at high soil temperature. J. Nematol. 18:491-495.

2. Barcala, M., Garcia, A., Cabrera, J., Casson, S., Lindsey, K., Favery, B., Garcia-Casado, G., Solano, R., Fenoll, C., and Escobar, C. 2010. Early transcriptomic events in microdissected Arabidopsis nematode-induced giant cells. Plant J. 61:698-712.

3. Bar-Orl, C., Kapulnik, Y., and Koltai, H. 2005. A broad characterization of the transcriptional profile of the compatible tomato response to the plant parasitic root knot nematode Meloidogyne javanica. Eur. J. Plant Pathol. 111:181-192.

4. Berthou, F., Ba-Diallo, A., De Maeyer, L., and De Guiran, G. 1989. Caracterisation chez les nematodes Meloidogyne Goeldi (Tylenchida) de rypes virulents vis avis du gene $M i$ de la tomate dans deux zones maraicheres au Senegal. Agronomie 9:877-884.

5. Bhattarai, K. K., Xie, Q. G., Mantelin, S., Bishnoi, U., Girke, T., Navarre, D. A., and Kaloshian, I. 2008. Tomato susceptibility to root-knot nematodes requires an intact jasmonic acid signaling pathway. Mol. PlantMicrobe Interact. 21:1205-1214.

6. Bleve-Zacheo, T., Melillo, M. T., and Castagnone-Sereno, P. 2007. The contribution of biotechnology to root-knot nematode control in tomato plants. Pest Technology 1:1-16.

7. Block, A., Schmelz, E., Jones, J. B., and Klee, H. J. 2005. Coronatine and salicylic acid: The battle between Arabidopsis and Pseudomonas for phytohormone control. Mol. Plant Pathol. 6:79-83.

8. Blok, V. C., Phillips, M. S., and Fargette, M. 1997. Comparison of sequences from the ribosomal DNA intergenic region of Meloidogyne mayaguensis and other major tropical root-knot nematodes. J. Nematol. 29:16-22.

9. Bost, S. C., and Triantaphyllou, A. C. 1982. Genetic basis of the epidemiologic effects of resistance to Meloidogyne incognita in the tomato cultivar Small Fry. J. Nematol. 14:540-544.

10. Bostock, R. M. 2005. Signal crosstalk and induced resistance: straddling the line between cost and benefit. Annu. Rev. Phytopathol. 43:545-580.

11. Branch, C., Hwang, C. F., Navarre, D. A., and Williamson, V. M. 2004. Salicylic acid is part of the Mi-1-mediated defense response to root-knot nematode in tomato. Mol. Plant-Microbe Interact. 17:351-356.

12. Castagnone-Sereno, P. 2002. Genetic variability of nematodes: a threat to the durability of plant resistance genes? Euphytica 124:193-199.

13. Castagnone-Sereno, P., Bongiovanni, M., and Dalmasso, A. 1993. Stable virulence against the tomato resistance $M i$ gene in the parthenogenetic root-knot nematode Meloidogyne incognita. Phytopathology 83:803-805.

14. Castagnone-Sereno, P., Bongiovanni, M., and Dalmasso, A. 1994. Reproduction of virulent isolates of Meloidogyne incognita on susceptible and Mi-resistant tomato. J. Nematol. 26:324-328.

15. Castagnone-Sereno, P., Esparrago, G., Abad, P., Leroy, F., and Bongiovanni, M. 1995. Satellite DNA as a target for PCR-specific detection of the plant-parasitic nematode Meloidogyne hapla. Curr. Genet. 28:566-570.

16. Ciancio, A., and Mukerji, K. G. 2008. Integrated Managment of Diseases Caused by Fungi, Phytoplasma and Bacteria, Vol. 3. Springer. The Netherlands.

17. Cooper, W. R., Jia, L., and Goggin, L. 2005. Effects of jasmonate-induced defenses on root-knot nematode infection of resistant and susceptible tomato cultivars. J. Chem. Ecol. 31:1953-1967.

18. del Pozo, O., Pedley, K. F., and Martin, G. B. 2004. MAPKKK $\alpha$ is a positive regulator of cell death associated with both plant immunity and disease. EMBO J. 23:3072-3082.

19. Djian-Caporalino, C., Molinari, S., Palloix, A., Ciancio, A., Fazari, A., Marteu, N., Ris, N., and Castagnone-Sereno, P. 2011. The reproductive potential of the root-knot nematode Meloidogyne incognita is affected by selection for virulence against major resistance genes from tomato and pepper. Eur. J. Plant Pathol. 131:431-440.

20. Dong, K., Dean, R. A., Fortnum, B. A., and Lewis, S. A. 2001. Development of PCR primers to identify species of root-knot nematodes: Meloidogyne arenaria, M. hapla, M. incognita, and $M$. javanica. Nematropica 31:271-280.

21. Eddaoudi, M., Ammati, M., and Rammah, A. 1997. Identification of the resistance breaking populations of Meloidogyne on tomatoes in Morocco and their effect on new sources of resistance. Fundam. Appl. Nematol. 20:285-289.

22. El Mehrach, K., Mejía, L., Gharsallah-Couchane, S., Salus, M. S., Martin, C. T., Hatimi, A., Vidavski, F., Williamson, V., and Maxwell, D. P. 2005. PCR-based methods for tagging the Mi-1 locus for resistance to root-knot nematode in begomovirus-resistant tomato germplasm. Acta Hortic. 695:263-270.

23. Fujimoto, T., Tomitaka, Y., Abe, H., Tsuda, S., Futai, K., and Mizukubo, T. 2011. Expression profile of jasmonic acid-induced genes and the induced resistance against the root-knot nematode (Meloidogyne incognita) in tomato plants (Solanum lycopersicum) after foliar treatment with methyl jasmonate. J. Plant Physiol. 168:1084-1097.

24. Garrido, J. M., Morcillo, R. J., Rodriguez, J. A., and Bote, J. A. 2010. Variations in the mycorrhization characteristics in roots of wild-type and ABA-deficient tomato are accompanied by specific transcriptomic alterations. Mol. Plant-Microbe Interact. 23:651-664.

25. Gheysen, G., and Fenoll, C. 2002. Gene expression in nematode feeding sites. Annu. Rev. Phytopathol. 40:191-219.

26. Gutjahr, C., and Paszkowski, U. 2009. Weights in the balance: jasmonic acid and salicylic acid signaling in root-biotroph interactions. Mol. PlantMicrobe Interact. 22:763-772.

27. Hartman, K. M., and Sasser, J. N. 1985. Identification of Meloidogyne species on the basis of differential host test and perineal pattern morphology. Pages 69-77 in: An Advanced Treatise on Meloidogyne, Volume II: Methodology. K. R. Barker, C. C. Carter, and J. N. Sasser, eds. North Carolina State University Graphics, Raleigh, U.S.A.

28. Huang, X., McGiffen, M., and Kaloshian, I. 2004. Reproduction of MiVirulent Meloidogyne incognita Isolates on Lycopersicon spp. J. Nematol. 36:69-75.

29. Hussey, R. S., and Baker, K. R. 1973. Comparison of methods of collecting inocula for Meloidogyne spp., including a new technique. Plant Dis. Rep. 57:1025-1028.

30. Iberkleid, I., Vieira, P., de Almeida Engler, J., Firester, K., Spiegel, Y., and Horowitz, S. B. 2013. Fatty acid-and retinol-binding protein, Mj-FAR-1 induces tomato host susceptibility to root-knot nematodes. PLoS One 8:e64586.

31. Ibrahim, Y. K. A. 1985. The status of root-knot nematodes in the middle east, region VII of the international Meloidogyne project. Pages 373-378 in: An Advanced Treatise on Meloidogyne, Volume II: Methodology. K. R. Barker, C. C. Carter, and J. N. Sasser, eds. North Carolina State University Graphics, Raleigh, U.S.A.

32. Jacquet, M., Bongiovanni, M., Martinez, M., Verschave, P., Wajnberg, E., and Castagnone-Sereno, P. 2005. Variation in resistance to the root-knot nematode Meloidogyne incognita in tomato genotypes bearing the $\mathrm{Mi}$ gene. Plant Pathol. 54:93-99.

33. Jansen van Vuuren, R., and Woodward, B. 2001. The response of cassava cultivars to root-knot nematode infestation: an in vitro method. Euphytica 120:109-113.

34. Jarquin-Barberena, H., Dalmasso, A., de Guiran, G., and Cardin, M. 1991. Acquired virulence in the plant parasitic nematode Meloidogyne incognita. 1. Biological analysis of the phenomenon. Rev. Nematol. 14:261-275.

35. Kaloshian, I., Williamson, V. M., Miyao, G., Lawn, D. A., and Westerdahl, B. B. 1996. Identification of "resistance breaking" field populations of root-knot nematodes on tomato in California. Calif. Agric. 50:18-20.

36. Kyndt, T., Denil, S., Haegeman, A., Trooskens, G., Bauters, L., Van Criekinge, W., De Meyer, T., and Gheysen, G. 2012. Transcriptional reprogramming by root knot and migratory nematode infection in rice. New Phytol. 196:887-900.

37. Lambert, K. N., Ferrie, B. J., Nombela, G., Brenner, E. D., and Williamson, V. M. 1999. Identification of genes whose transcripts accumulate rapidly in tomato after root-knot nematode infection. Physiol. Mol. Plant Pathol. 55:341-348. 
38. Lamberti, F. 1981. Plant nematode problems in the Mediterranean region. Helminthol. Abstr. Ser. B Plant Nematol. 50:145-166.

39. Laterrot, H. 1975. Sélection pour la résistance au mildiou, Phytophthora infestans Mont., de Bary chez la tomate. Ann. Amelior. Plant. 25:129-149.

40. Maleita, C. M., Vieira dos Santos, M. C., Curtis, R. H. C., Powers, S. J., and Abrantes, I. M. de O. 2011. Effect of the Mi gene on reproduction of Meloidogyne hispanica on tomato genotypes. Nematology 13:939-949.

41. Meher, H. C., Gajbhiye, V. T., Chawla, G., and Singh, G. 2009. Virulence development and genetic polymorphism in Meloidogyne incognita (Kofoid \& White) Chitwood after prolonged exposure to sublethal concentrations of nematicides and continuous growing of resistant tomato cultivars. Pest Manage. Sci. 65:1201-1207.

42. Melillo, M. T., Leonetti, P., Bongiovanni, M., Castagnone-Sereno, P., and Bleve-Zacheo, T. 2006. Modulation of reactive oxygen species activities and $\mathrm{H}_{2} \mathrm{O}_{2}$ accumulation during compatible and incompatible tomato-rootknot nematode interactions. New Phytol. 170:501-512.

43. Molinari, S., and Miacola, C. 1997. Interaction between resistant tomato cvs and Meloidogyne spp. in vitro. Nematol. Mediterr. 25:63-71.

44. Nahar, K., Kyndt, T., De Vleesschauwer, D., Hofte, M., and Gheysen, G. 2011. The jasmonate pathway is a key player in systemically induced defense against root knot nematodes in rice. Plant Physiol. 157:305-316.

45. Oka, Y., Ben-Daniel, B. H., and Cohen, Y. 2006. Control of Meloidogyne javanica by formulations of inula viscosa leaf extracts. J. Nematol. 38:4651.

46. Oka, Y., Offenbach, R., and Pivonia, S. 2004. Pepper rootstock graft compatibility and response to Meloidogyne javanica and $M$. incognita. J. Nematol. 36:137-141.

47. Ornat, C., Verdejo-Lucas, S., and Sorribas, F. J. 2001. A population of Meloidogyne javanica in Spain virulent to the $M i$ resistance gene in tomato. Plant Dis. 85:271-276.

48. Philis, J. 1983. Occurrence of Meloidogyne spp. and races on the island of Cyprus. Nematol. Mediterr. 11:13-19.

49. Philis, J., and Vakis, N. 1977. Resistance of tomato varieties to the rootknot nematode Meloidogyne javanica in Cyprus. Nematol. Mediterr. 5:3944.

50. Puthoff, D. P., Nettleton, D., Rodermel, S. R., and Baum, T. J. 2003. Arabidopsis gene expression changes during cyst nematode parasitism revealed by statistical analyses of microarray expression profiles. Plant $\mathrm{J}$. 33:911-921.

51. Riggs, R. D., and Winstead, N. N. 1959. Studies on resistance in tomato to root-knot nematodes and on the occurrence of pathogenic biotypes. Phytopathology 49:716-724.

52. Roberts, P. A., Dalmasso, A., Cap, G. B., and Castagnone-Sereno, P. 1990. Resistance in Lycopersicon pentvianum to isolates of $\mathrm{Mi}$ gene compatible Meloidogyne populations. J. Nematol. 22:585-589.

53. Roberts, P. A., and Thomason, I. J. 1986. Variability in reproduction of isolates of Meloidogyne incognita and M. javanica on resistant tomato genotypes. Plant Dis. 70:547-551.

54. Rojo, E., Solano, R., and Sanchez-Serrano, J. J. 2003. Interactions between signaling compounds involved in plant defense. Plant Growth Regul. 22:82-98.

55. Sambrook, S., and Russell, D. W. 1989. Molecular Cloning: A Laboratory Manual, 2nd ed. Cold Spring Harbor Laboratory Press, Cold Spring Harbor, NY.
56. Schaff, J. E., Nielsen, D. M., Smith, C. P., Scholl, E. H., and Bird, D. M. 2007. Comprehensive transcriptome profiling in tomato reveals a role for glycosyltransferase in $\mathrm{Mi}$-mediated nematode resistance. Plant Physiol. 144:1079-1092.

57. Seah, S., Telleen, A. C., and Williamson, V. M. 2007. Introgressed and endogenous $\mathrm{Mi}-\mathrm{l}$ gene clusters in tomato differ by complex rearrangements in flanking sequences and show sequence exchange and diversifying selection among homologues. Theor. Appl. Genet. 114:12891302.

58. Sellami, S., Lonici, M., Eddoud, A., and Besenghir, H. 1999. Distribution et plantes hotes associées aux Meloidogyne sous abris plastiques en Algerie. (Distribution and host plants of Meloidogyne in plastic houses in Algeria.) Nematol. Mediterr. 27:295-301.

59. Sijmons, P. C., Grundler, F. M. W., Von Mende, N., Burrows, P. R., and Wyss, U. 1991. Arabidopsis thaliana as a new model host for plant parasitic nematodes. Plant J. 1:245-254.

60. Smith, P. G. 1944. Embryo culture of a tomato species hybrid. Proc. Am. Soc. Hortic. Sci. 44:413-416.

61. Soriano, I. R., Riley, I. T., Potter, M. J., and Bowers, W. S. 2004. Phytoecdysteroids: a novel defense against plant-parasitic nematodes. J. Chem. Ecol. 30:1885-1899.

62. Tarjan, A. C. 1953. Geographical distribution of some Meloidogyne species in Israel. Plant Dis. Rep. 37:315-316.

63. Taylor, D. P., and Netscher, C. 1974. An improved technique for preparing perineal patterns of Meloidogyne spp. Nematologica 20:268-269.

64. Triantaphyllou, A. C. 1985. Gametogenesis and the chromosomes of Meloidogyne nataliei: not typical of other root-knot nematodes. J. Nematol. 17:1-5.

65. Tzortzakakis, E. A., Adam, M. A. M., Blok, V. C., Paraskevopoulos, C., and Bourtzis, K. 2005. Occurrence of resistance-breaking populations of root-knot nematodes on tomato in Greece. Eur. J. Plant Pathol. 113:101105.

66. Tzortzakakis, E. A., and Gowen, S. R. 1996. Occurrence of a resistancebreaking pathotype of Meloidogyne javanica on tomatoes in Crete, Greece. Fundam. Appl. Nematol. 19:283-288.

67. Tzortzakakis, E. A., Trudgill, D. L., and Phillips, M. S. 1998. Evidence for a dosage effect of the $M i$ gene on partially virulent isolates of Meloidogyne javanica. J. Nematol. 30:76-80.

68. Van Loon, L. C., Rep, M., and Pieterse, C. M. J. 2006. Significance of inducible defense-related proteins in infected plants. Annu. Rev. Phytopathol. 44:135-162.

69. Williamson, V. M., Ho, J. Y., Wu, F. F., Miller, N., and Kaloshian, I. 1994. A PCR-based marker tightly linked to the nematode resistance gene, $\mathrm{Mi}$, in tomato. Theor. Appl. Genet. 87:757-763.

70. Williamson, V. M., and Roberts, P. A. 2009. Mechanisms and Genetics of Resistance. Pages 301-321 in: Root-knot Nematodes. R. N. Perry, M. Moens, and J. L. Starr, eds. CAB International, Oxfordshire, UK.

71. Young, R. J., Scheuring, C. F., Harris-Haller, L., and Taylor, B. H. 1994. An auxin-inducible proteinase inhibitor gene from tomato. Plant Physiol. 104:811-812.

72. Zijlstra, C., Donkers-Venne, D. T. H. M., and Fargette, M. 2000. Identification of Meloidogyne incognita, M. javanica and M. arenaria using sequence characterised amplified region (SCAR) based PCR assays. Nematology 2:847-853. 